\title{
Cryostructuring of Polymeric Systems. 52. Properties, Microstructure and an Example of a Potential Biomedical Use of the Wide-Pore Alginate Cryostructurates
}

\author{
Natalia D. Zvukova ${ }^{1}$, Tamara P. Klimova ${ }^{1}$, Roman V. Ivanov ${ }^{1}$, Andrei N. Ryabev ${ }^{1}$, \\ Archil V. Tsiskarashvili ${ }^{2}$ and Vladimir I. Lozinsky ${ }^{1, *}$ \\ 1 A.N. Nesmeyanov Institute of Organoelement Compounds, Russian Academy of Sciences, Vavilov Street, 28, \\ 119991 Moscow, Russia; natalya_zvukova@mail.ru (N.D.Z.); tab@ineos.ac.ru (T.P.K.); \\ erawell@mail.ru (R.V.I.); ryabev@ineos.ac.ru (A.N.R.) \\ 2 N.N. Priorov National Medical Research Center of Traumatology and Orthopedics, Ministry of Health of the \\ Russian Federation, Priorov Street, 10., 127299 Moscow, Russia; armed05@mail.ru \\ * Correspondence: loz@ineos.ac.ru; Tel.: +7-499-135-6492
}

Received: 29 March 2019; Accepted: 7 May 2019; Published: 9 May 2019

\begin{abstract}
Wide-pore cryostructurates were prepared via freezing sodium alginate aqueous solutions with subsequent ice sublimation from the frozen samples, followed by their incubation in the ethanol solutions of calcium chloride or sulfuric acid, rinsing, and final drying. Such sequence of operations resulted in the calcium alginate or alginic acid sponges, respectively. The swelling degree of the walls of macropores in such matrices decreased with increasing polymer concentration in the initial solution. The dependence of the degree of swelling on the cryogenic processing temperature had a bell-like character with a maximum for the samples formed at $-20{ }^{\circ} \mathrm{C}$. According to ${ }^{1} \mathrm{H}$ NMR spectroscopy, the content of mobile (non-frozen) water in the frozen water-sodium alginate systems also depended on the initial polymer concentration and freezing temperature. The cryostructurates obtained did not lose their integrity in water, saline, in an acidic medium at pH 2 for at least three weeks. Under alkaline conditions at $\mathrm{pH} 12$ the first signs of dissolution of the Ca-alginate sponge arose only after a week of incubation. Microbiological testing of the model depot form of the antibiotics entrapped in the Ca-alginate cryostructurate demonstrated the efficiency of this system as the antibacterial material.
\end{abstract}

Keywords: cryostructurates; sodium alginate; calcium alginate; alginic acid; freeze-drying; swelling characteristics; microstructure; antibacterial material

\section{Introduction}

Polymeric cryostructurates are the macroporous materials of spongy morphology, which are formed as a result of freezing the solutions of macromolecular precursors or certain gels with subsequent removal of the crystallized solvent phase without thawing the system as a whole [1]. In this context, two types of cryostructurates can be distinguished [2]:

(I) In the first case, a cryostructurate is produced by freezing a molecular or colloidal polymer solution followed by removing the polycrystals of the solvent by sublimation or cryoextraction. As a rule, the resulting porous material is soluble. Therefore, to convert it into an insoluble form, either additional chains crosslinking (chemical or radiation) or the respective chemical modification of functional groups of the polymer is required.

(II) Upon the preparation of the second type of cryostructurates, the already-formed gel is frozen and then the solvent crystals are removed, most often via sublimation, as, for example, in the production of so-called "freeze-dried food" or some lyophilized pharmaceuticals [3,4]. 
In both cases, no gel formation occurs in the frozen samples, which distinguishes cryostructurates from cryogels, the formation of a three-dimensional spatial network of which, on the contrary, is triggered by freezing the precursor solution and proceeds exactly in a frozen medium $[1,2,5,6]$.

Polymeric cryostructurates are of great interest both as objects of basic research and as materials for applications. The physico-chemical properties and macroporous morphology of various cryostructurates are determined by many factors, including the nature of the precursors, their concentration in the feed system (before cryogenic processing), the conditions of freezing, and removal of the crystalline phase, the methods of imparting insolubility to cryostructurates of the above-indicated type (I) [1-4,7-11].

For instance, these polymeric matrices include polyelectrolyte cryostructurates formed according to a three-stage scheme: freezing a solution of polyelectrolyte-removing the crystallized solvent phase-transforming the polymer into an insoluble form (either using the crosslinking counterions or by recharging the ionogenic groups of macromolecular chains) $[5,12,13]$. In this context, cryostructurates and cryogels based on natural polymers such as ionic polysaccharides, in particular, alginic acid (the copolymer of $\beta$-D-mannuronic and $\alpha$-L-guluronic acids) and its salts, attract the increasing attention during recent years, especially upon the elaboration of biomedical and biotechnological materials [14-22], in food technology [23], environment protection [24], etc. This is determined, firstly, by the availability and low cost of alginates; secondly, by their biocompatibility, nontoxicity, and non-immunogenicity; thirdly, by the good gel-forming properties, which, like the characteristics of the obtained gel materials, can be controlled by choosing a polymer with the required molecular weight, ratio, and blockiness of monomeric units, as well as the nature and concentration of the crosslinking counterions [25-28].

Conventional alginate hydrogels are formed upon the introduction of divalent or trivalent metal cations into the aqueous solutions of the sodium salt of this polyelectrolyte [25-31]. In turn, alginic acid gels are formed when the alginate solution is acidified below the $\mathrm{pK}_{\mathrm{a}}$ value of the uronic units of this biopolymer [32]. Since the ionotropic gelation of alginates is a very fast process that proceeds almost immediately after the components are mixed, it is technically difficult to carry out the gelation exactly in a frozen system (this is precisely what is needed to obtain cryogels [5]), because the formation of a spatial polymer network occurs earlier than the system freezes. Simultaneously, the forming solvent crystals are capable of disrupting the integrity of the low-strength network. Therefore, alginate cryogels can be obtained from solutions only with a rather low concentration of precursors.

The alternatives are the type (I) alginate cryostructurates, when the content of components in the system depends only on the solubility of the alginic acid salt used to prepare the starting solution of this polyelectrolyte. It was shown that this approach is very effective for obtaining spongy alginate cryostructurates [12] that were used as a polymeric base of the wide-pore scaffolds for the three-dimensional cultivation, differentiation, and cryopreservation of stem cells [33,34], as well as were employed as the carriers for the medicamental nano-forms [35]. The latter studies revealed a rather prospective applied potential of such alginate sponges for the elaboration of wound dressings (these experiments are in progress now; their results will be reported in the subsequent publication). Therefore, there was the necessity for a systematic study of the factors influencing the properties and macroporous morphology of such alginate cryostructurates with the aim of fine controlling their characteristics. This opens the routes for the experimentally based selection of these materials in solving specific problems of their use, e.g., as the polymer carriers for drugs, in particular, antibiotics. Exactly such research was the goal of this work, and we mainly interested in the properties of wet and swollen alginate sponges since upon their use as the wound dressings, where the materials operate in aqueous media. 


\section{Results and Discussion}

\subsection{Influence of Formation Conditions on the Properties of Ca-Alginate and Alginic Acid Cryostructurates}

As it is known, the factors mainly influencing the physicochemical properties of any polymeric cryostructurates of the type (I) essentially include the concentration of the macromolecular precursor in the feed solution and the temperature conditions of its cryogenic treatment [1,2,5,8-10]. For this reason, we studied the dependence of the characteristics of alginate and alginic cryostructurates on these parameters. The schematic diagram of their formation is illustrated in Figure 1, and the method for their preparation is described in the "Experimental".

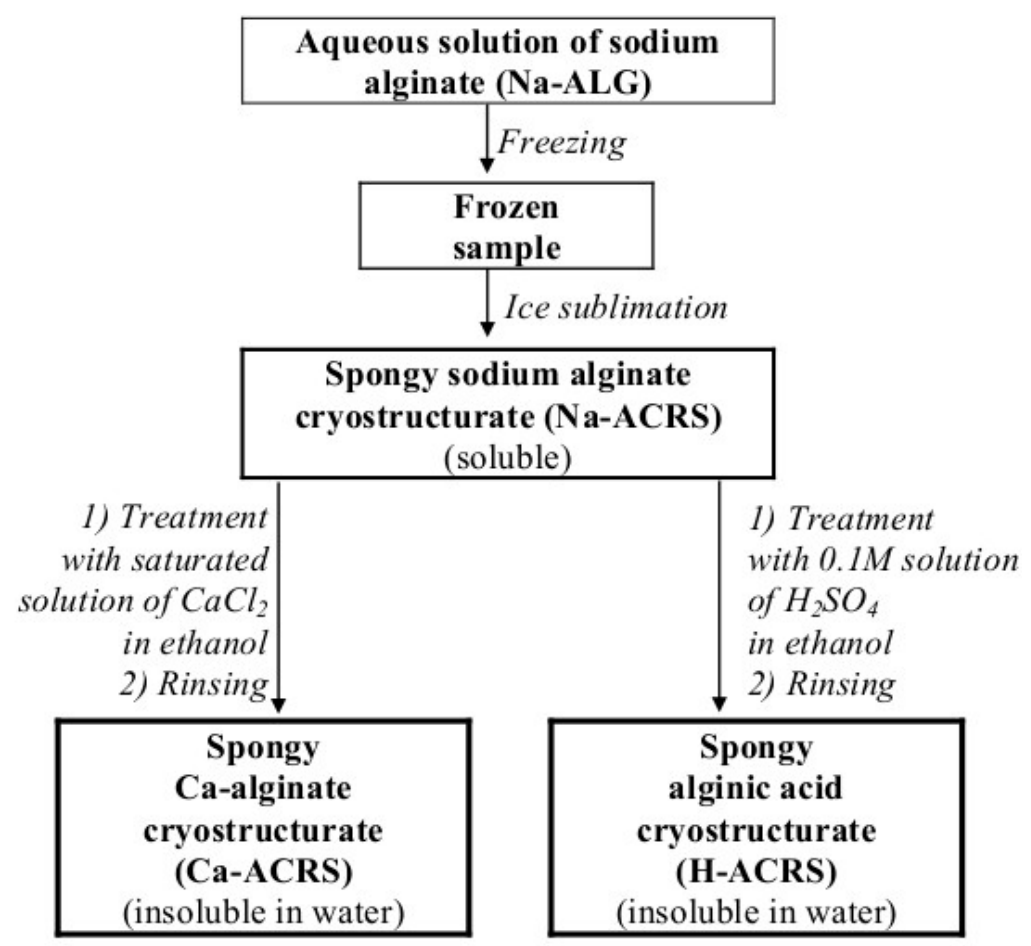

Figure 1. Schematic diagram of the preparation of Ca-alginate and alginic acid cryostructurates.

Preliminary experiments showed that calcium-alginate cryostructurates (Ca-ACRS) and alginic acid cryostructurates (H-ACRS) that possessed the properties convenient for further research can be formed from the sodium alginate (Na-ALG) aqueous solutions in the range of polymer concentrations from 10 to $50 \mathrm{~g} / \mathrm{L}$. At a lower initial polysaccharide concentration, rather weak cryostructurates were formed that had low strength in the swollen state. On the other hand, when the concentration of $\mathrm{Na}-\mathrm{ALG}$ was above the indicated range, a considerable increase in the viscosity of the stock polymer solution took place thus significantly complicating its dosing. As for the freezing conditions of the Na-ALG solutions, at negative temperatures above $-10{ }^{\circ} \mathrm{C}$ the system often did not crystallize because of the supercooling effects. In turn, the samples freezing below $-30{ }^{\circ} \mathrm{C}$ caused a marked decrease in the pore cross-section of the resultant cryostructurates, especially prepared from the solutions with a polymer concentration of 40-50 g/L. Therefore, in the course of further research, the feed solutions of sodium alginate were frozen at a temperature over the range from -10 to $-30{ }^{\circ} \mathrm{C}$.

After ice sublimation from the frozen samples, the resultant sodium alginate cryostructurate (Na-ACRS) was converted either to calcium salt (Ca-ACRS) or to acidic form (H-ACRS) to impart them the insolubility in water. This treatment was carried out in an ethanol medium which wetted the polymer well, but did not dissolve it, i.e., the replacement of $\mathrm{Na}^{+}$counterions for $\mathrm{Ca}^{2+}$ or $\mathrm{H}^{+}$ cations, respectively, actually occurred in the solid phase without disturbing the spongy morphology of the material. In contrast, if to carry out such ion-exchange processes in an aqueous medium, an 
undesirable swelling or even partial dissolution of the polymer can occur. In turn, in ethanol, thus "insolubilized" Ca-ACRS and H-ACRS cryostructurates were tough, while after replacing ethanol with water and achieving equilibrium swelling, they became rather soft sponges. As a result, a free fluid from the interconnected wide pores could be pressed out, for example, on a glass filter under vacuum (see "Experimental"). This property of the water-swollen Ca-alginate and alginic acid cryostructurates, i.e., squeezing of capillary liquid by mechanical action, does not allow the correct measurement of the physico-mechanical characteristics of the swollen matrices, but it makes possible to evaluate the degree of swelling ( $S_{\mathrm{w} / \mathrm{w}}, \mathrm{g} \mathrm{H}_{2} \mathrm{O} / \mathrm{g}$ polymer) of their polymeric phase, i.e., the walls of macropores. This procedure was successfully employed earlier for various cryogenically structured macroporous spongy materials based on polymers of both synthetic [5,36-41], and natural (chitosan [42-44], agarose [45,46], albumin $[9,47]$, gelatin $[10,48]$, etc.) origin. In the case of alginate-containing cryostructurates, the $S_{\mathrm{w} / \mathrm{w}}$ values were determined for samples formed from the solutions of different Na-ALG concentrations. The data obtained in these experiments are shown in the graphs of Figure 2 in the form of the dependences of the swelling degree values for Ca-ACRS (a) and H-ACRS (b) on the polymer concentration in the solution before its freezing at $-20^{\circ} \mathrm{C}$.

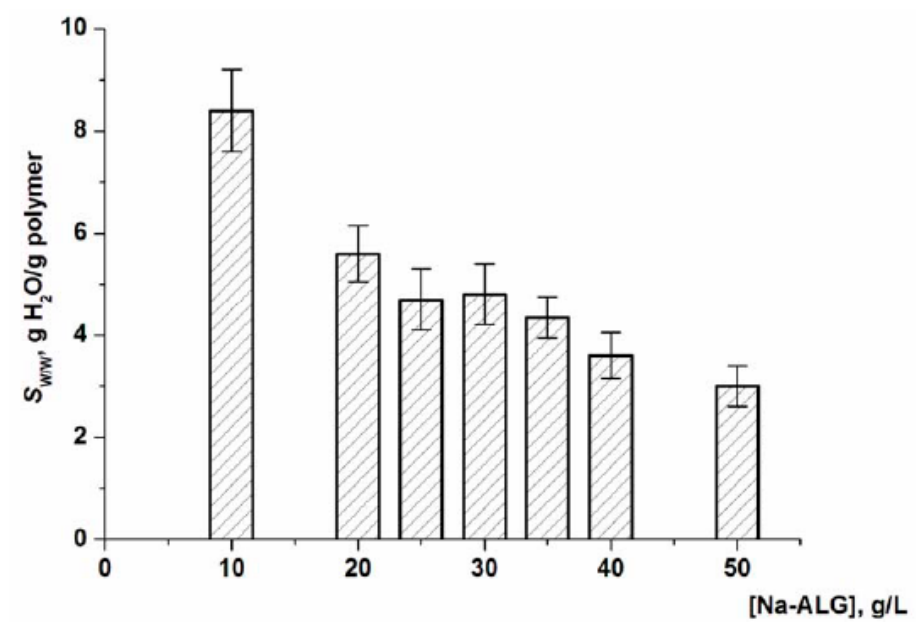

(a)

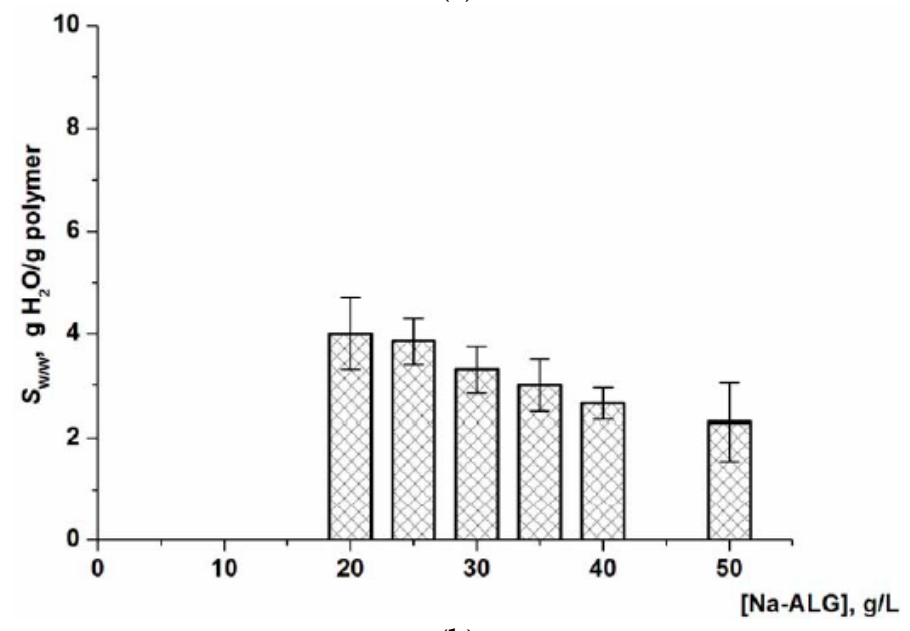

(b)

Figure 2. The swelling degree of the polymeric matter in the walls of macropores in Ca-ACRS (a) and H-ACRS (b) samples formed by freezing at $-20{ }^{\circ} \mathrm{C}$ of aqueous polymer solutions of different Na-ALG concentrations.

The common trend for both Ca-ACRS and N-ACRS was a decrease in the swelling degree of the polymeric phase in these spongy cryostructurates as the initial concentration of Na-ALG increased. This indicates that the use of a more concentrated solution of a polysaccharide precursor 
results in a heterophase material with denser walls of macropores, where the polymer chains are cross-linked with calcium ions in Ca-ACRS or via the hydrogen bonds such as "carboxyl-hydroxyl" and "hydroxyl-hydroxyl" in H-ACRS. In the latter case, alginic acid sponges, prepared according to the scheme of Figure 1 from a $10 \mathrm{~g} / \mathrm{L} \mathrm{Na-ALG} \mathrm{solution,} \mathrm{were} \mathrm{rather} \mathrm{weak.} \mathrm{Therefore,} \mathrm{it} \mathrm{was} \mathrm{not} \mathrm{possible} \mathrm{to}$ determine correctly their swelling degree. In turn, the absolute values of the parameter $S_{\mathrm{w} / \mathrm{w}}$ equal to 5.7-3.0 $\mathrm{g} \mathrm{H}_{2} \mathrm{O}$ per $1 \mathrm{~g}$ of dry matter in the polymeric phase of Ca-alginate sponges formed from the 20-50 g/L Na-ALG solutions (Figure 2a) were approximately 20-30\% higher $(2.5-4.1 \mathrm{~g} / \mathrm{g}$ ) than the values for the corresponding H-ACRS sponges (Figure $2 b$ ). This fact indicates a slightly greater hydration of the walls of macropores in the Ca-ACRS, i.e., the affinity of water molecules to calcium alginate is, obviously, higher than that in respect with the protonated form of alginic acid.

It is well-recognized that one of the key factors determining the properties and porous morphology of polymeric matrices formed using the cryogenic structuring approaches is the temperature conditions of freezing of the initial liquid system [1-6,49-52]. Therefore, we evaluated the influence of freezing temperature of the sodium alginate aqueous solution on the degree of swelling of the polymeric phase in the resultant cryostructurates. The data obtained for the Ca-ACRS samples formed from a polysaccharide solution with $[\mathrm{Na}-\mathrm{ALG}]=30 \mathrm{~g} / \mathrm{L}$ are shown in Figure 3 .

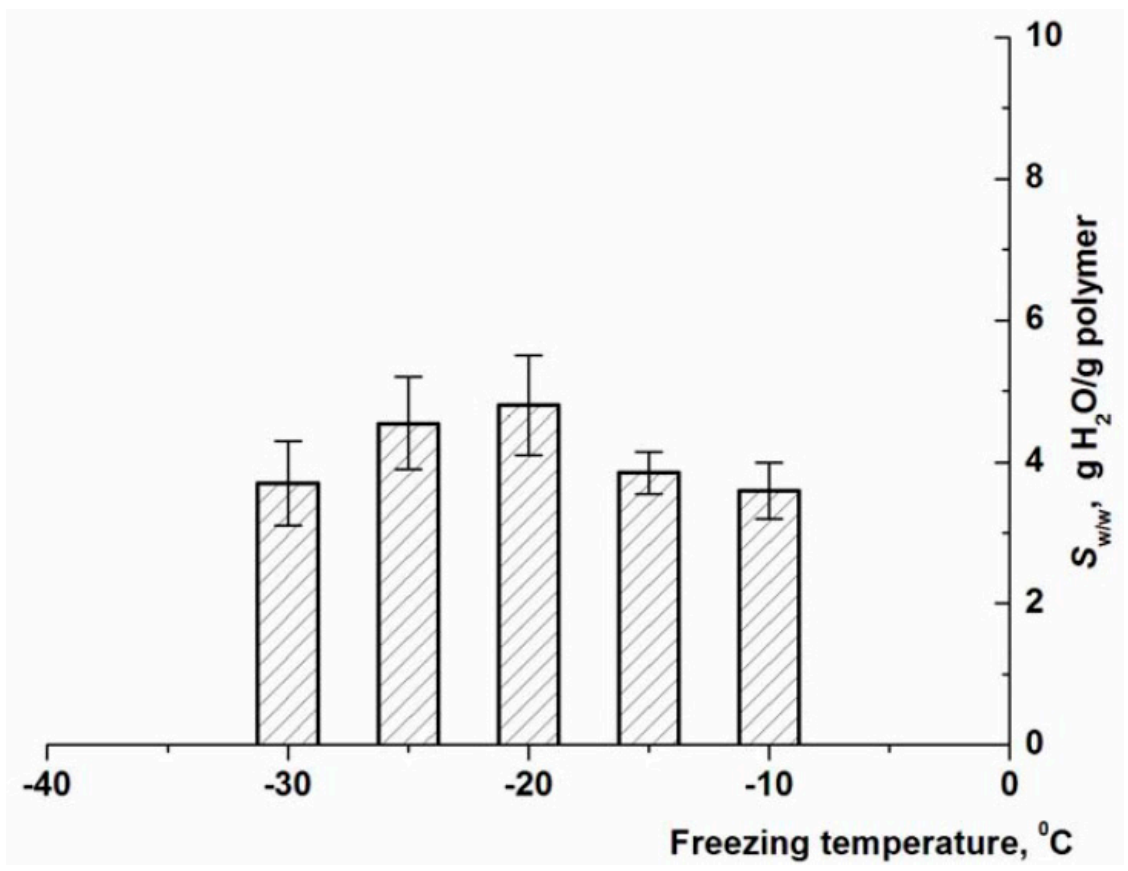

Figure 3. The swelling degree of the polymeric matter in the walls of macropores of Ca-ACRS samples formed by freezing the Na-ALG solution $(30 \mathrm{~g} / \mathrm{L})$ at different negative temperatures.

It turned out that such temperature dependence had a bell-shaped character, when the walls of macropores of a spongy cryostructurate formed by freezing at $-20^{\circ} \mathrm{C}$ swelled to the greatest extent $\left(S_{\mathrm{w} / \mathrm{w}} \approx 4.9 \mathrm{~g} / \mathrm{g}\right)$. The polymeric phase of the wide-pore samples prepared via freezing at both above (i.e., -15 and $\left.-10{ }^{\circ} \mathrm{C}\right)$ and below $\left(-25\right.$ and $\left.-30{ }^{\circ} \mathrm{C}\right)$ this temperature swelled to a lesser extent (3.6-3.8 $\mathrm{g} / \mathrm{g}$ ). The similar extreme nature of the temperature effect of the frozen system on the osmotic properties (swelling) of the macropore walls in the cryogenically structured heterophase matrices was previously described, for example, for chitosan cryogels [53], which evidence the very close temperature effects. The reason is the competition of oppositely-directed processes [1,5]. In particular, the lower is the temperature of the frozen solvent-polymer system, the higher is the concentration of the polymer in the volume of a so-called unfrozen liquid microphase (UFLMP) $[54,55]$ due to the freezing out a larger solvent volume. Therefore, there is a higher probability of intermolecular contacts, as well as overlapping of the chains with the formation of topological entanglements, which contributes to 
the compaction of the polymer phase. As a result, the walls of macropores in the already-formed cryostructurate will swell weaker at positive temperatures. On the other hand, the lower is the temperature of the frozen sample, the higher is the viscosity of its UFLMP, which significantly limits the mobility of macromolecules and their segments, thus preventing the compaction of the polymeric phase in the "future" spongy cryostructurate. This kind of competition results in bell-shaped dependencies of the properties of cryogenically structured polymer matrices on the temperature of cryogenic treatment of the initial systems in general and the dependence of the degree of swelling of Ca-ACRS samples on the freezing temperature of the Na-ALG solution in particular (Figure 3). In turn, regarding the potential biomedical application of the drug-loaded alginate sponges, the ratio of the loaded drug amount inside the capillary pores and within the polymeric gel phase of pore walls will depend on their (the walls) swelling extent. This ratio should influence on the drug release kinetics-quick from the intrapore space and somewhat slower from the pore walls.

In this regard, interesting data were obtained in the NMR measurements of the mobile water content in the non-deeply frozen $\left(-10,-20\right.$ and $\left.-30^{\circ} \mathrm{C}\right)$ sodium alginate solutions of different initial polymer concentration $(20,30$, and $35 \mathrm{~g} / \mathrm{L})$. The results of these experiments are given in Figure 4 as the temperature dependence of the parameter $\alpha$-the ratio of the areas of the signals for the water protons in the frozen samples and the signals recorded at room temperature for the solutions of the same polymer concentrations (see "Experimental").

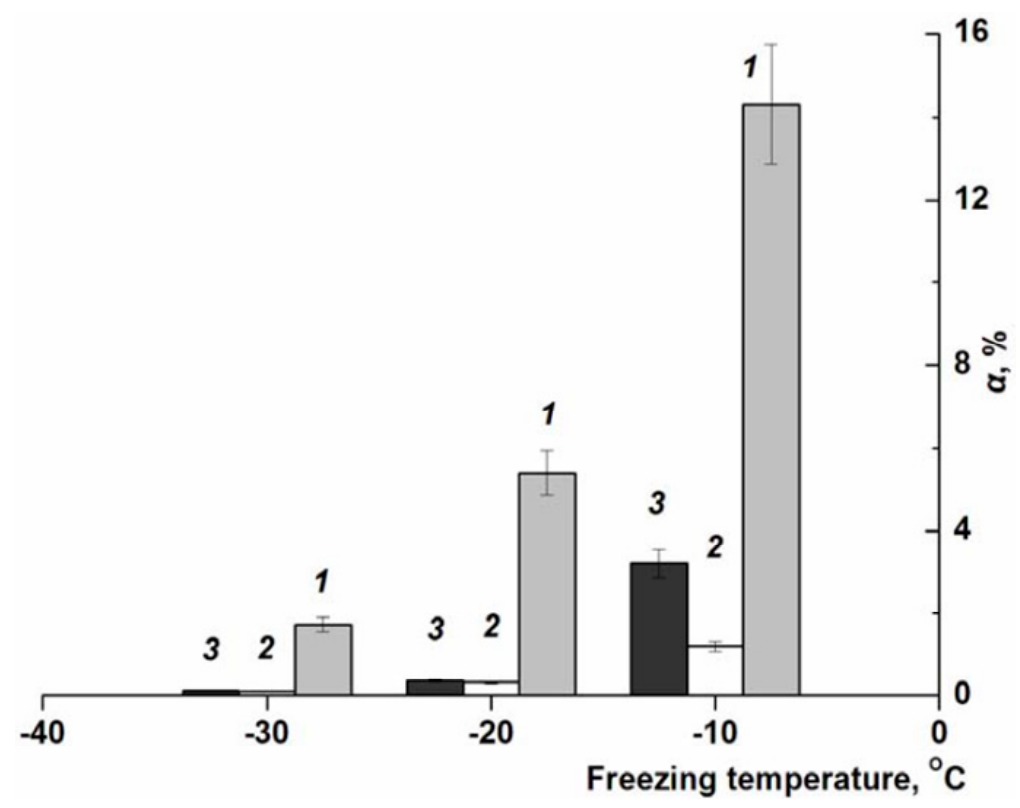

Figure 4. Relative content $(\alpha)$ of mobile (nonfrozen) water in the macroscopically frozen aqueous Na-ALG solutions of different concentrations of the polymer: 20 (1), 30 (2), and 35 (3) g/L, when the samples have been frozen at various minus temperatures.

The content of nonfrozen water at different subzero temperatures for the initially equiconcentrated Na-ALG systems systematically decreased with lowering the temperature from -10 to $-30^{\circ} \mathrm{C}$, which is understandable, since the lower is the temperature of the frozen sample, the greater the amount of solvent crystallizes. However, in relation to the influence of polymer concentration in the frozen systems on the $\alpha$ parameter no direct dependence was observed. At three negative temperatures used the lowest content of nonfrozen water, which retains mobility according to the NMR data, was found in the case of a system with an initial polymer concentration of $30 \mathrm{~g} / \mathrm{L}(2 ;$ Figure 4$)$. In the samples with an initial Na-ALG concentration of 20 and $35 \mathrm{~g} / \mathrm{L}$ (1 and 3, respectively; Figure 4), at each minus temperature the content of the nonfrozen water was higher. 
There is still not enough data to interpret this fact accurately, but at a qualitative level, such concentration dependence (with a minimum) indicates, most probably, the competitive nature of the processes that ultimately determine the phase equilibrium in frozen aqueous Na-ALG solutions. In similar moderately frozen systems, one of the key factors is the viscosity of the UFLMP, since the higher is the initial polymer concentration, the higher will be the viscosity of the unfrozen fraction in a macroscopically frozen sample because the dissolved substances are concentrated in the UFLMP. It is known that the crystallization of the solvent during its freezing in highly viscous media occurs with significant hindrances [56]. On the other hand, it cannot be ruled out that the probability of the glass transition for some part of the UFLMP increases with lowering the temperature, thereby reducing the content of mobile water, and this factor is also included in the "competition" with other factors. In any case, the experimental data testify to the "consequences" of such competition, which is reflected in the properties of cryostructurates formed on the basis of solutions of different concentrations of the polymer precursor and at different temperatures of the cryogenic stage.

\subsection{Macroporous Morphology of Alginate Cryostructurates}

As it is well-known $[1-6,36,37,39,42,45-47,49-51,57,58]$, the temperature conditions of the cryostructuring of polymer systems exerts a significant influence on the texture of the resulting heterophase matrices, as well as on the volume fraction, size, and shape of their macropores. Therefore, we studied the features of the macroporous morphology of alginate cryostructurates formed at the same freezing temperatures of the polysaccharide solutions in comparison with the samples the osmotic characteristics of which (Figure 3) were discussed above. As an example, Figure 5 shows the micrographs (optical microscope) of Ca-ACRSs prepared by freezing the $30 \mathrm{~g} / \mathrm{L}$ Na-ALG aqueous solution at $-10,-20$, and $-30^{\circ} \mathrm{C}$.

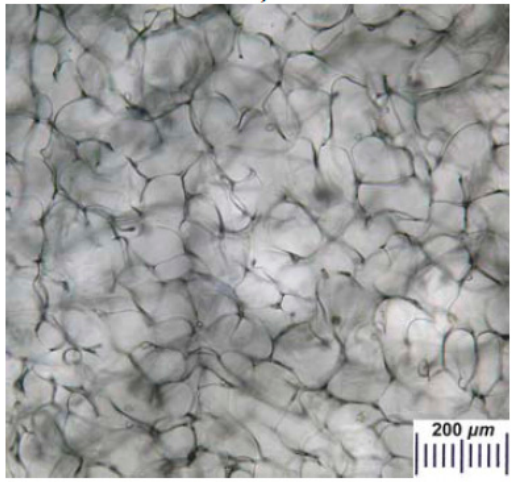

(a)

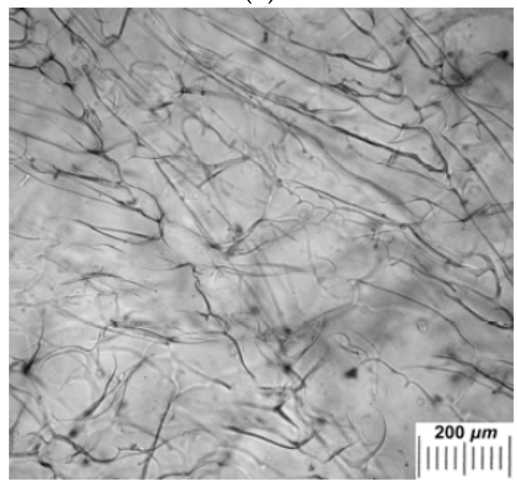

(c)

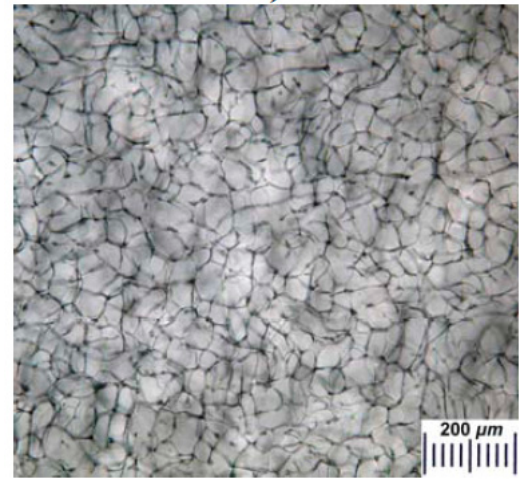

(b)

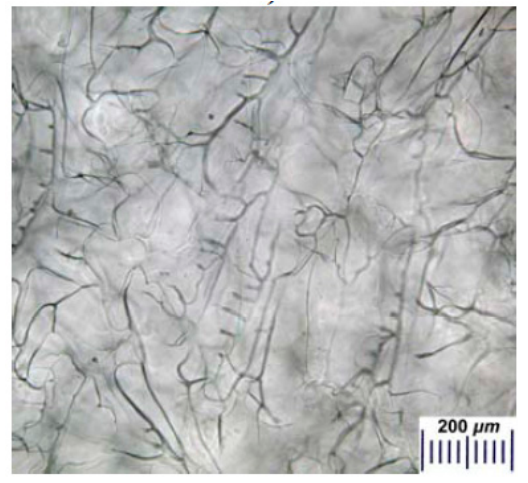

(d)

Figure 5. Micrographs (optical microscope) of the water-swollen Ca-ACRS samples formed on the basis of an aqueous Na-ALG solution $(30 \mathrm{~g} / \mathrm{L})$ by its freezing at the following temperatures: $-10{ }^{\circ} \mathrm{C}(\mathbf{a})$ the bottom surface of the disk; $-20^{\circ} \mathrm{C}(\mathbf{b})$ the bottom surface of the disk and (d) the top surface disk; and $-30{ }^{\circ} \mathrm{C}(\mathrm{c})$ the bottom surface of the disk. 
An analysis of such images indicates that the size and shape of macropores in these alginate matrices are not entirely dependent directly on the freezing temperature. Thus, the pores in the Ca-ACRS sponge formed at $-10{ }^{\circ} \mathrm{C}$ had a cross-section from 65 to $160 \mu \mathrm{m}$ (Figure 5a), and in a cryostructurate formed at $-20^{\circ} \mathrm{C}$, this interval was from 40 to $110 \mu \mathrm{m}$ (Figure $5 \mathrm{~b}$ ), i.e., with lowering the freezing temperature a well-known regularity was observed, which is stipulated by a diminution of the porogen (ice polycrystals) size with a deeper cooling of the system under freezing $[16,57,58]$. At the same time, at even lower freezing temperature, in particular, at $-30^{\circ} \mathrm{C}$, the cryogenically-structured samples with very irregular porosity with respect to the geometry of the macropores and their sizes were formed (Figure 5c). This result indicates a sophisticated nature of the "low-temperature" freezing even of a rather thin layer $(\sim 2 \mathrm{~mm})$ of sodium alginate solution being in a plastic Petri dish placed on a cooled plate (see "Experimental"). In this context, it could not be excluded that along with the ice crystallization within the freezing sample, a partial glass transition processes can (as it was pointed out above) occur upon rapid cooling [58], thus interfering the movement of the solvent crystallization fronts. It is clear that this assumption requires additional study, which was not the task of the present work.

The samples for the microscopy observation were prepared in the shape of flat disks, and the micrographs in the Figure 5a-c display the texture of the bottom surface of each disk, which, when the stock solution of polysaccharide was frozen, contacted with the bottom of the cooled Petri dish. Therefore, the temperature gradient had a vertical direction, when the solvent crystallization front moved upwards. At the same time, due to the "branched" nature of the growth of ice crystals $[56,59,60]$, the pores in the upper part of the flat cryostructurates, firstly, greatly change their shape and become significantly larger than those in the lower part, and, secondly, the overall texture becomes less regular. Exactly the same (at the qualitative level) pattern of certain differences in the macroporous morphology of the upper and lower regions of flat freeze-structured polymer matrices was observed for cryogels and cryostructurates based on agarose [45,61], serum albumin [9,47], gelatin [10], poly(vinyl alcohol) [62], and some others [49-51,63-65]. In the case of alginate cryostructurates, a very similar tendency was also met. For example, it is well-detected when comparing the micrographs in Figure $5 b$,d, showing the morphology of the lower and upper surfaces, respectively, of the Ca-ACRS disc formed by freezing at $-20{ }^{\circ} \mathrm{C}$.

\subsection{Behavior of Alginate Cryostructurates in Aqueous Media of Different Composition}

As it was already noted, alginate-containing cryostructurates are promising materials in terms of their use for solving a number of biomedical and biotechnological problems. In such cases, the "operation" of these matrices usually takes place in aqueous media of various composition. Therefore, it is important to have the data on the stability or, conversely, the destruction of such polysaccharide sponges in the respective liquids. To this end, we observed the preservation of the integrity of the Ca-ACRS disks when they were incubated for three weeks in one of the following fluids:

- In the deionized water (control);

- In the $0.15 \mathrm{M}$ aqueous solution of $\mathrm{NaCl}$ (saline), i.e., in the conditions promoting the shift of the ion exchange equilibrium towards the replacement of calcium ions in $\mathrm{Ca}$-alginate by $\mathrm{Na}^{+}$-ions due to the excess of the latter ones and, as a consequence, the possible solubilization of the polymer;

- In the $0.01 \mathrm{~N} \mathrm{HCl}$ solution at $\mathrm{pH} 2$, where the transformation of Ca-ACRS to H-ACRS should take place, but without dissolving the polymer framework of the cryostructurate;

- In the $0.01 \mathrm{~N} \mathrm{NaOH}$ solution at $\mathrm{pH} 12$, i.e., under the conditions where conventional Ca-alginate hydrogels are dissolved rather quickly [16].

The results obtained in these experiments are shown in the photographs of Figure 6, where one can see the appearance of the test samples during their incubation in the above-indicated milieus. As a result, it was found that these spongy cryostructurates are stable not only in water (Figure 6a-d) and acidic medium (Figure 6i-l), where neither Ca-alginate nor alginic acid dissolve, but also in an excess of $\mathrm{Na}^{+}$-ions in physiological solution (Figure $6 \mathrm{e}-\mathrm{h}$ ). Only in an alkaline medium at $\mathrm{pH} 12$ a very slow 
(starting approximately from the middle of the second week of the experiment) solubilization of the polymer material was observed (Figure $6 \mathrm{~m}-\mathrm{p}$ ).

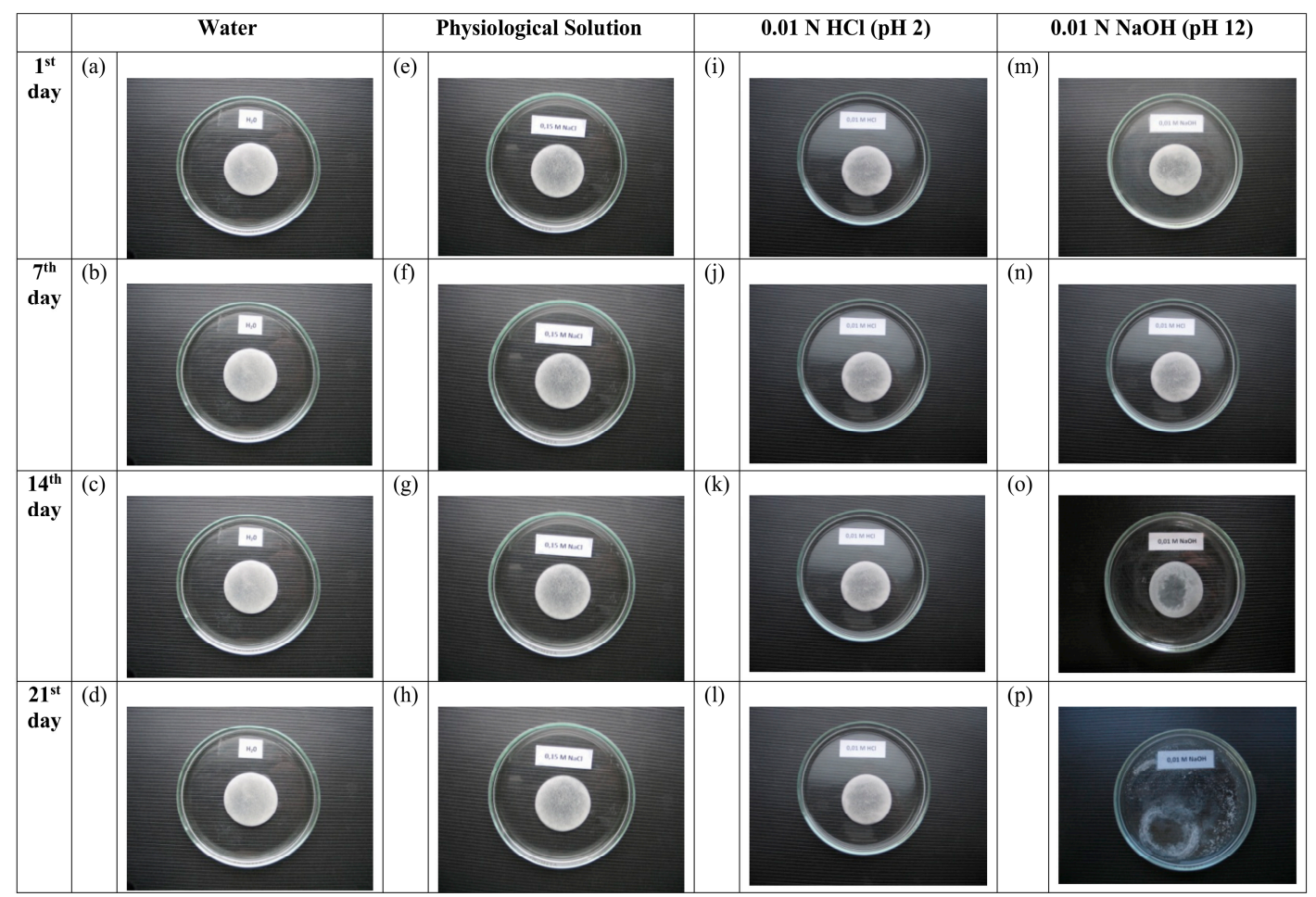

Figure 6. Appearance of the Ca-ACRS disks prepared by freezing at $-20{ }^{\circ} \mathrm{C}$ of an aqueous Na-ALG solution $(30 \mathrm{~g} / \mathrm{L})$, when the resultant disks were incubated in the liquid media of different composition. The symbols $(\mathbf{a}-\mathbf{p})$ indicate the particular samples are under discussion within the text.

Such a high stability of the Ca-ACRS sponges, as well as the H-ACRS matrices in an acidic medium, formed according to the sequence of operations we used (Figure 1), most likely is due to the fact that crosslinking of the alginate chains with calcium ions or intermolecular hydrogen bonding of the uronic acid groups occurred within the bulk of the highly concentrated polymeric walls of macropores of the spongy matrix poorly swollen (wetted) in ethanol. In this case in the condensed phase of the walls of macropores, the functional groups of the macromolecular chains are very close together, which should contribute to the formation of a dense frequently crosslinked polymeric network. In contrast, in the usual cases of ionotropic alginate gelation, when the crosslinking process proceeds in solution [14-16,25-28] where the solvated polymer chains are distant from each other, only some fraction of their functional groups can be involved in the intermolecular binding.

It may also be noted that at the qualitative level there is a similar tendency, i.e., the maximum possible degree of crosslinking of macromolecules in the condensed phase of the walls of macropores, was found in the case of the cryogenically structured protein sponges formed by freezing aqueous solutions of serum albumin, their subsequent freeze-drying and further chemical tanning with the carbodiimide reagent in an ethanol medium [9]. Hence, one can draw the conclusion that the preparation of the wide-pore polymer matrices according to the scheme for the formation of the type (I) cryostructurates (Figure 1) makes it possible to increase the stability of the polymer phase of such spongy materials with respect to various solubilizing factors.

\subsection{In Vitro Testing of Ca-Alginate Cryostructures as a Polymeric Carrier for the "Depot Form" of Antibiotics}

In modern medical practice, in particular, in the treatment of wounds and burns, spongy coatings containing medicinal agents, frequently called "depot forms" of appropriate medicines, are widely employed [66,67]. Such wide-pore materials perform several functions: Absorption of liquid 
exuded by a wound, protection of the wound from contact with the environment, as well as the delivery of the medication to the lesion. Since certain alginate materials are permitted for medical use $[16,17,68-71]$, we conducted a primary in vitro assessment of the possible biomedical potential of the Ca-ACRS/vancomycin depot formulations using the standard diffusion test (see "Experimental"). To assess the antimicrobial activity of such formulation, a culture of methicillin-resistant microorganism belonging to the species of Staphylococcus aureus was used. Figure 7 shows an example of such testing.

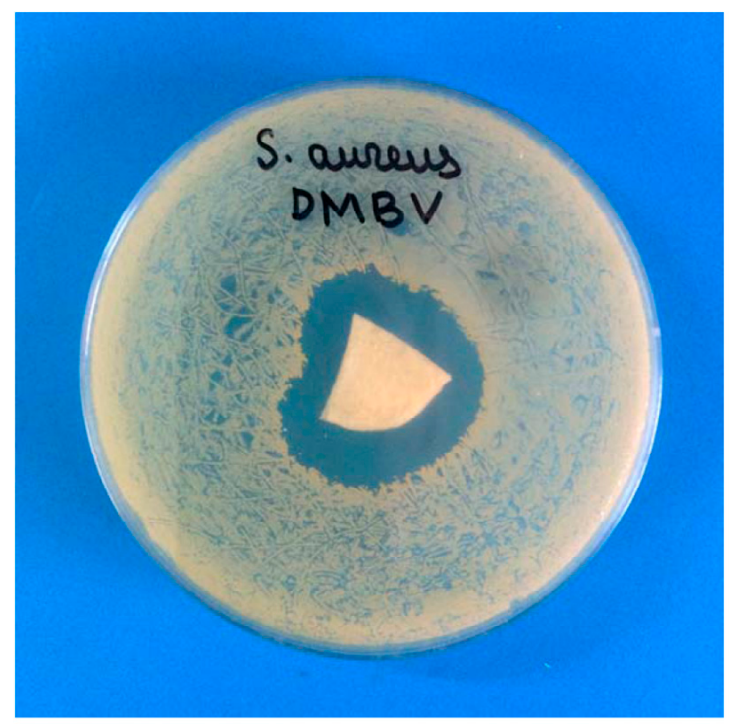

Figure 7. The result of the diffusion test, which demonstrates the formation of the zone of inhibition of the growth of bacteria Staphylococcus aureus caused by the release of vancomycin from the Ca-alginate sponge.

The technique used in these experiments makes it possible to visualize the release of a drug (in our case, an antibiotic) from the polymeric carrier [35]. As a result, a growth suppression zone of bacterial culture colonies on an agar nutrient medium is formed. Such zone of clearing is visible well in the photograph of Figure 7 around the sector of the Ca-alginate sponge loaded with vancomycin $(\sim 93 \mathrm{mg}$ per a spongy disk of $38 \mathrm{~mm}$ in diameter and $\sim 2 \mathrm{~mm}$ thickness). The sector was cut from the disc. In turn, on the control Petri dish with the same staphylococcal colonies, in the center of which was located a fragment of a spongy Ca-ACSR without an antibiotic, the formation of the growth suppression zone was not observed at all. Thus, in these experiments, the performance of the alginate sponges as the polymeric carriers for antibiotics was shown, which indicates the prospects for the biomedical use of similar depot forms of antibacterial medications.

\section{Conclusions}

Currently, alginic acid and its salts are widely employed in various fields of human activity, especially in food and biomedical technologies. In the former case, these ionic polysaccharides are used as the functional ingredients and the polymer base of some food forms (jelly products), in the latter case-as the biomedical materials (covers on wounds and burns, scaffolds for cell culture, etc.). In this regard, of a certain scientific and applied interest is the preparation of alginate materials using the methods of cryostructuring of macromolecular systems. This is because such approach allows obtaining the wide-pore polymer matrices with a developed system of interconnected large pores. In the present work, this method was used to create spongy alginic acid and calcium-alginate cryostructurates that were prepared by freezing at $-10 \ldots-30^{\circ} \mathrm{C}$ sodium alginate aqueous solutions $(10-50 \mathrm{~g} / \mathrm{L})$, followed by sublimation of ice from the frozen samples, the treatment of freeze-dried spongy matrices with, respectively, ethanol solution of sulfuric acid or calcium chloride, washing the resultant sponges and their final drying in vacuum. It was found that the degree of swelling of the walls of macropores in 
such matrices decreases with increasing the polymer concentration in the initial solution. With that, the dependence of the degree of swelling on the cryogenic treatment temperature has a bell-like character with a maximum for the samples formed by freezing at $-20{ }^{\circ} \mathrm{C} .{ }^{1} \mathrm{H}$ NMR spectroscopic studies of frozen sodium alginate solutions showed that the content of mobile (non-frozen) water therein also depends on the initial concentration of the polymer and the temperature of the cryogenic treatment. The cryostructurates obtained in this work were stable in aqueous media, i.e., for at least three weeks the sponges did not lose their integrity in water, saline, and in an acidic medium at $\mathrm{pH} 2$. In an alkaline medium at $\mathrm{pH} 12$, the first signs of dissolution of the Ca-alginate sponge arose only after a week-long incubation. Microbiological testing of a model depot form of an antibiotic (vancomycin) entrapped in the wide porous Ca-alginate cryostructurate demonstrated the efficiency of this composite system thus testifying the prospects of creating such depot forms of various medicinal agents using cryogenically structured polymer carrier based on this biocompatible and affordable polysaccharide.

\section{Experimental}

\subsection{Materials}

The following substances and preparations were used without additional purification: Sodium alginate (Na-ALG) (BDH Chemicals Ltd., Poole, UK) (MM $150 \mathrm{kDa}$; the viscosity of the $1 \%$ aqueous solution $0.63 \mathrm{~Pa} \cdot \mathrm{s}\left(23^{\circ} \mathrm{C}\right)$; the content of mannuronic blocks was $30 \%$, the content of guluronic blocks was $20 \%$, and the content of the mixed sequence blocks was 50\% [26]), calcium chloride (anhydrous, Panreac, Barcelona, Spain), vancomycin (Teva Pharmaceutical Industries Ltd., Petah Tikva, Israel), sulfuric acid (chemically pure, IREA-2000 Ltd., Moscow, Russian), 95\% ethyl alcohol (Khimmed, Moscow, Russian), sodium hydroxide (Chemapol, Prague, Czech Republic), hydrochloric acid 38\% (Reakhim, Moscow, Russian), and physiological saline (JSC Biochemist, Moscow, Russian). Deionized water was used to prepare polymer solutions.

\subsection{Preparation of Alginate and Alginic Cryostructurates}

The cryostructurates were formed from the aqueous solutions of Na-ALG $(10-50 \mathrm{~g} / \mathrm{L})$ that were initially filtered under vacuum through a porous glass filter, and then treated for $30 \mathrm{~min}$ in an ultrasonic bath UM-1 (Unitra-Unima, Warsaw, Poland) for removing air bubbles. Next, the polymer solution in portions of $2.25 \mathrm{~g}$ was poured into plastic Petri dishes (Medpolymer, Moscow, Russian) with an inner diameter of $38 \mathrm{~mm}$. The dishes were placed in the chamber of a Proline RP 1840 ultracryostat (Lauda, Königshofen, Germany) and kept for $1 \mathrm{~h}$ to freeze the liquid at a pre-set temperature $(-10 ;-15 ;-20$; -25 ; or $\left.-30^{\circ} \mathrm{C}\right)$, after which the ice was sublimated in vacuo $(0.040 \mathrm{mbar})$ for $18 \mathrm{~h}$ using an Alpha 1-2 LD plus freeze-drier (Martin Christ, Osterode am Harz, Germany). Then, in order to obtain the water-insoluble Ca-alginate cryostructurates (Ca-ACRS in Figure 1), the freeze-dried spongy Na-ALG discs were immersed for $24 \mathrm{~h}$ in a saturated ethanol solution of $\mathrm{CaCl}_{2}$, further rinsed with an excess of alcohol and finally dried in vacuo at $1 \mathrm{~mm} \mathrm{Hg}$. For obtaining of the water-insoluble alginic acid cryostructurates (H-ACRS in Figure 1) the spongy Na-ALG discs were immersed for $24 \mathrm{~h}$ in a $0.1 \mathrm{M}$ ethanol solution of $\mathrm{H}_{2} \mathrm{SO}_{4}$, rinsed with alcohol, and dried in vacuo like the Ca-ACRS samples.

\subsection{Characterization of the Cryostructurates}

The swelling degree of the polymeric phase (the walls of macropores) in the wide-pore Ca-alginate and alginic acid cryostructurates was determined by the gravimetric method. To do this, free liquid was removed from the water-swollen sponges on a glass filter under vacuum of a water-jet pump. Thus obtained "pressed-out" wet samples were weighed and then dried at $110^{\circ} \mathrm{C}$ to a constant weight in an air thermostat SNOL 24/200 (AB Utenos Elektrotechnika, Utena, Lithuania). The degree of swelling by weight $\left(S_{\mathrm{w} / \mathrm{w}}\right)$ was calculated by the formula:

$$
S_{\mathrm{w} / \mathrm{w}}=\left(m_{\mathrm{wet}}-m_{\mathrm{dry}}\right) / m_{\mathrm{dry}}\left(\mathrm{g} \mathrm{H}_{2} \mathrm{O} / \mathrm{g} \text { polymer }\right)
$$


where $m_{\text {wet }}$ is the mass of the "pressed-out" wet sample, $m_{\text {dry }}$ is the mass of the dry sample.

When studying the stability of alginate cryostructurates in different liquid media, each of the Ca-ACRS samples was kept in one of the following solutions: $0.15 \mathrm{M} \mathrm{NaCl}, 0.01 \mathrm{~N} \mathrm{NaOH}, 0.01 \mathrm{~N} \mathrm{HCl}$, and $\mathrm{H}_{2} \mathrm{O}$. The liquid phase was replaced with a fresh portion weekly. The state of cryostructurates was recorded using an $\alpha-750$ digital photocamera (Sony, Tokyo, Japan).

The macroporous morphology of alginate cryostructures was studied using an Eclipse 55i optical microscope (Nikon, Tokyo, Japan) equipped with a digital image recording system.

\subsection{NMR Studies}

The quantitative measurements of the unfrozen water fraction in frozen Na-ALG solutions was performed by the ${ }^{1} \mathrm{H}$ NMR method using an AMX TM 300 spectrometer (Brüker, Hardt, Germany) at an operating frequency of $313 \mathrm{MHz}$. Aqueous solution of the polymer $(20,30$, or $35 \mathrm{~g} / \mathrm{L})$ was placed in a polyethylene capillary (internal diameter $0.85 \mathrm{~mm}$ ) with a sealed lower end. The capillary was put in a standard NMR ampoule containing deutero-acetone. The signals of protons of the solvent (water) were recorded at $-10,-20$, and $-30^{\circ} \mathrm{C}$ and their areas were found. Then, their ratio $(\alpha)$ to the areas of the proton signals of Na-ALG solutions of the same concentrations recorded at room temperature was calculated and expressed as a percentage.

\subsection{Microbiological Tests}

To load the polysaccharide cryostucturates with the antibiotic, dry Ca-ACRS sponges were placed in an aqueous solution of vancomycin $(50 \mathrm{~g} / \mathrm{L})$ and incubated for $24 \mathrm{~h}$ at $4{ }^{\circ} \mathrm{C}$ with periodical stirring. Then the swollen sponges were frozen at $-20^{\circ} \mathrm{C}$ and freeze-dried. The amount of the antibiotic in thus prepared sponge has been determined gravimetrically as the difference in the weight of dry sponge before its loading with vancomycin and the weight after loading and freeze-drying. This amount turned out to be $93.4 \pm 0.8 \mathrm{mg}$ per a spongy disk of $38 \mathrm{~mm}$ in diameter and $\sim 2 \mathrm{~mm}$ thickness. The antimicrobial activity of the already obtained antibiotic "depot forms" obtained was determined by the diffusion method according to the protocol described elsewhere [35] using the Staphylococcus aureus DMBV test culture from the collection of microorganisms of the National Medical Research Center of Traumatology and Orthopedics.

Author Contributions: N.D.Z.- preparation of the cryostructurates and measurements of their swelling values, preparation of the manuscript; T.P.K.-NMR studies of frozen systems; R.V.I.- elaboration of the procedure for loading the sponges with antibiotic; A.N.R.-microscopic studies of porous morphology of the cryostructurates; A.V.T.- microbiological testing of the drug-loaded sponges; V.I.L.-planning of studies and their supervising, preparation of the manuscript.

Funding: This research was partly funded by the Russian Science Foundation and by the Presidium of the Russian Academy of Sciences.

Acknowledgments: The work on obtaining of alginate cryostructurates and studying their physicochemical properties was supported by a grant from the Russian Science Foundation (project No. 16-13-10-365); the biotests of the corresponding depot forms were carried out as part of the project of the Presidium of the Russian Academy of Sciences on the program "Basic research for the development of biomedical technologies for 2018 -2020 years".

Conflicts of Interest: The authors declare no conflict of interest.

\section{References}

1. Lozinsky, V.I. A brief history of polymeric cryogels. Adv. Polym. Sci. 2014, 263, 1-48. [CrossRef]

2. Lozinsky, V.I. Cryostructuring of polymeric systems. 50. Cryogels and cryotropic gel-formation: terms and definitions. Gels 2018, 4, 77. [CrossRef]

3. Lawrence, R.; Consolacion, F.; Jelen, P. Formation of structured protein foods by freeze texturization. Food Technol. 1986, 40, 77-90.

4. Geidobler, R.; Winter, G. Controlled ice nucleation in the field of freeze-drying: Fundamentals and technology review. Eur. J. Pharm. Biopharm. 2013, 85, 214-222. [CrossRef] 
5. Lozinsky, V.I. Cryogels on the basis of natural and synthetic polymers: Preparation, properties and areas of implementation. Russ. Chem. Rev. 2002, 71, 489-511. [CrossRef]

6. Okay, O. (Ed.) Polymeric Cryogels: Macroporous Gels with Remarkable Properties; Springer: Cham, Switzerland, 2014; 330p, ISBN 978-3-319-05845-0.

7. Travan, A.; Scagnamiglio, F.; Borgogna, M.; Marsich, E.; Donati, I.; Tarusha, L.; Grassi, M.; Paoletti, S. Hyaluronan delivery by polymer demixing in polysaccharide-based hydrogels and membranes for biomedical applications. Carbohydr. Polym. 2016, 150, 408-418. [CrossRef] [PubMed]

8. Jiang, S.; Agarwal, S.; Greiner, A. Low-density open cellular sponges as functional materials. Angew. Chem. Int. Ed. 2017, 56, 15520-15538. [CrossRef]

9. Rodionov, I.A.; Grinberg, N.V.; Burova, T.V.; Grinberg, V.Y.; Shabatina, T.I.; Lozinsky, V.I. Cryostructuring of polymer systems. 44. Freeze-dried and then chemically cross-linked wide porous cryostructurates based on serum albumin. e-Polymers 2017, 17, 263-274. [CrossRef]

10. Lozinsky, V.I.; Kulakova, V.K.; Ivanov, R.V.; Petrenko, A.Y.; Rogulska, O.Y.; Petrenko, Y.A. Cryostructuring of polymer systems. 47. Preparation of wide porous gelatin-based cryostructurates in sterilizing organic media and assessment of the suitability of thus formed matrices as spongy scaffolds for 3D cell culturing. e-Polymers 2018, 18, 175-186. [CrossRef]

11. Fu, H.; Chen, J.; Chen, L.; Zhu, X.; Chen, Z.; Qiu, B.; Lin, Z.; Guo, L.; Chen, G. A calcium alginate sponge with embedded gold nanoparticles as a flexible SERS substrate for direct analysis of pollutant dyes. Mikrochim. Acta 2019, 186, 64. [CrossRef]

12. Lozinsky, V.I.; Simenel, I.A.; Chebyshev, A.V. Method for the production of porous polymeric materials. Russia Patent No. 2,035,476, 1994.

13. Lozinsky, V.I.; Zubov, A.L. Method for the preparation of macroporous polymeric material. Russ. Pat. No. 2,078,099, 1994.

14. Gacesa, P. Alginates. Carbohydr. Polym. 1988, 8, 161-182. [CrossRef]

15. Smidstrød, O.; Skjåk-Bræk, G.S. Alginates as immobilization matrix for cells. Trends Biotechnol. 1990, 8, 71-78. [CrossRef]

16. Draget, K.I. Alginates. In Handbook of Hydrocolloids, 2nd ed.; Phillips, G.O., Williams, P.A., Eds.; Woodhead Publ. Ltd.: Cambridge, UK, 2009; pp. 807-829. ISBN 978-1-84569-414-2.

17. Lee, K.Y.; Mooney, D.J. Alginate: Properties and biomedical applications. Progr. Polym. Sci. 2012, 37, $106-126$. [CrossRef]

18. Nussinovitch, A.; Hirashima, M. Alginates. In Cooking Innovations Using Hydrocolloids for Thickening, Gelling and Emulsification; CRC Press: Boca Raton, FL, USA, 2013; pp. 35-55. ISBN 9781439875889.

19. Borda, L.J.; Macquhae, F.E.; Kirsner, R.S. Wound Dressings: A comprehensive review. Curr. Dermatol. Rep. 2016, 5, 287-297. [CrossRef]

20. Szekalska, M.; Pucilowska, A.; Szymanska, E.; Ciosek, P.; Winnicka, K. Alginate: Current use and future perspectives in pharmaceutical and biomedical applications. Int. J. Polym. Sci. 2016, 2016, 7697031. [CrossRef]

21. Gurikov, P.; Smirnova, A. Non-conventional methods for gelation of alginate. Gels 2018, 4, 14. [CrossRef]

22. Catanzano, O.; Soriente, A.; La Gatta, A.; Cammarota, M.; Ricci, G.; Fasolino, I.; Schiraldi, C.; Ambrosio, L.; Malinconico, M.; Laurienzo, P.; et al. Macroporous alginate foams crosslinked with strontium for bone tissue engineering. Carbohydr. Polym. 2018, 202, 72-83. [CrossRef]

23. Castro-Rosas, J.; Ferreira-Grosso, C.R.; Gomez-Aldapa, C.A.; Rangel-Vargas, E.; Rodriguez-Marin, M.L.; Guzman-Ortiz, F.A.; Falfan-Cortes, R.N. Recent advances in microencapsulation of natural sources of antimicrobial compounds used in food - A review. Food Res. Int. 2017, 102, 575-587. [CrossRef]

24. Wang, B.; Wan, Y.S.; Zheng, Y.L.; Lee, X.Q.; Liu, T.Z.; Yu, Z.B.; Huang, J.; Ok, Y.S.; Chen, J.J.; Gao, B. Alginate-based composites for environmental applications: A critical review. Crit. Rew. Environ. Sci. Technol. 2019, 49, 318-356. [CrossRef]

25. Grant, G.T.; Morris, R.E.; Reed, D.A.; Smith, P.J.P.; Thom, D. Biological interactions between polysaccharides and divalent cations: the egg-box model. FEBS Lett. 1973, 32, 195-198. [CrossRef]

26. Yuryev, V.P.; Grinberg, N.V.; Braudo, E.E.; Tolstoguzov, V.B. A study of the boundary conditions for the gel formation of alginates of polyvalent metals. Stärke 1979, 31, 121-124. [CrossRef]

27. Morris, E. Molecular interactions in polysaccharide gelation. Br. Polym. J. 1986, 18, 14-21. [CrossRef] 
28. Nussinovitch, A.; Velezsilvestre, R.; Peleg, M. Compressive characteristics of freeze-dried agar and alginate gel sponges. Biotechnol. Prog. 1993, 9, 101-104. [CrossRef]

29. Braccini, I.; Pérez, S. Molecular basis of $\mathrm{Ca}^{2+}$-induced gelation in alginates and pectins: The egg-box model. Biomacromolecules 2001, 2, 1089-1096. [CrossRef] [PubMed]

30. Draget, K.I.; Skjåk-Bræk, G.; Smidsrød, O. Alginic acid gels: the effect of alginate chemical composition and molecular weight. Carbohydr. Polym. 1994, 25, 31-38. [CrossRef]

31. Mørch, Ý.A.; Donati, I.; Strand, B.L.; Skjåk-Bræk, G. Effect of $\mathrm{Ca}^{2+}, \mathrm{Ba}^{2+}$ and $\mathrm{Sr}^{2+}$ on alginate microbeads. Biomacromolecules 2006, 7, 1471-1480. [CrossRef]

32. Zhao, Y.; Shen, W.; Chen, Z.; Wu, T. Freeze-thaw induced gelation of alginates. Carbohydr. Polym. 2016, 148, 45-51. [CrossRef]

33. Petrenko, Yu.A.; Ivanov, R.V.; Petrenko, A.Yu.; Lozinsky, V.I. Coupling of gelatin to inner surfaces of pore walls in spongy alginate-based scaffolds facilitates the adhesion, growth and differentiation of human bone marrow mesenchymal stromal cells. J. Mater. Sci. Mater. Med. 2011, 22, 1529-1540. [CrossRef]

34. Katsen-Globa, A.; Meiser, I.; Petrenko, Yu.A.; Ivanov, R.V.; Lozinsky, V.I.; Zimmermann, H.; Petrenko, A.Yu. Towards ready-to-use 3-D scaffolds for regenerative medicine: adhesion-based cryopreservation of human mesenchymal stem cells attached and spread within alginate-gelatin cryogel scaffolds. J. Mater. Sci. Mater. Med. 2014, 25, 857-871. [CrossRef]

35. Vernaya, O.I.; Shabatin, V.P.; Nuzhdina, A.V.; Zvukova, N.D.; Khvatov, D.I.; Semenov, A.M.; Lozinsky, V.I.; Shabatina, T.I.; Mel'nikov, M.Ya. Cryochemical synthesis and antibacterial activity of hybrid nanocomposites based on dioxidine containing $\mathrm{Ag}$ and $\mathrm{Cu}$ nanoparticles incorporated in biopolymer cryostructurates. Russ. Chem. Bull. 2017, 66, 2152-2156. [CrossRef]

36. Lozinsky, V.I.; Vainerman, E.S.; Korotaeva, G.F.; Rogozhin, S.V. Study of cryostructurization of polymer systems. III. Cryostructurization in organic media. Coll. Polym. Sci. 1984, 262, 617-622. [CrossRef]

37. Lozinsky, V.I.; Morozova, S.A.; Vainerman, E.S.; Titova, E.F.; Shtil'man, M.I.; Belavtseva, E.M.; Rogozhin, S.V. Study of cryostructurization of polymer systems. VIII. Characteristic features of the formation of crosslinked poly(acrylamide) cryogels under different thermal conditions. Acta Polym. 1989, 40, 8-15. [CrossRef]

38. Zhang, X.-Z.; Zhuo, R.-X. Preparation of fast responsive, temperature-sensitive poly( $N$-isopropylacrylamide) hydrogel. Macromol. Chem. Phys. 1999, 200, 2602-2605. [CrossRef]

39. Plieva, F.M.; Karlsson, M.; Aguilar, M.-R.; Gomez, D.; Mikhalovsky, S.; Galaev, I.Y. Pore structure in supermacroporous polyacrylamide based cryogels. Soft Matter 2005, 1, 303-309. [CrossRef]

40. Zhai, M.; Ma, F.; Li, J.; Wan, B.; Yu, N. Preparation and properties of cryogel based on poly(hydroxypropyl methacrylate). J. Biomater. Sci. Polym. Edn. 2018, 29, 1401-1425. [CrossRef]

41. Kudaibergenov, S.E. Physicochemical, complexation and catalytic properties of polyampholyte cryogels. Gels 2019, 5, 8. [CrossRef]

42. Lozinsky, V.I.; Vainerman, E.S.; Rogozhin, S.V. Study of cryostructurization of polymer systems. II. The influence of freezing of a reacting mass on the properties of products in the preparation of covalently cross-linked gels. Colloid Polym. Sci. 1982, 260, 776-780. [CrossRef]

43. Kirsebom, H.; Aguilar, M.R.; San Roman, J.; Fernandez, M.; Prieto, M.A.; Bondar, B. Macroporous scaffolds based on chitosan and bioactive molecules. J. Bioact. Compat. Polym. 2007, 22, 621-636. [CrossRef]

44. Bratskaya, S.; Privara, Y.; Slobodyuk, A.; Shashura, D.; Marinin, D.; Mironenko, A.; Zheleznov, V.; Pestov, A. Cryogels of carboxyalkylchitosans as a universal platform for the fabrication of composite materials. Carbohydr. Polym. 2019, 209, 1-9. [CrossRef] [PubMed]

45. Lozinsky, V.I.; Damshkaln, L.G.; Bloch, K.O.; Vardi, P.; Grinberg, N.V.; Burova, T.V.; Grinberg, V.Ya. Cryostructuring of polymer systems. XXIX. Preparation and characterization of supermacroporous (spongy) agarose-based cryogels used as three-dimensional scaffolds for culturing insulin-producing cell aggregates. J. Appl. Polym. Sci. 2008, 108, 3046-3062. [CrossRef]

46. Plieva, F.M.; Galaev, I.Y.; Mattiasson, B. Macroporous polysaccharide gels. In Macroporous Polymers. Production Properties and Biotechnological/Biomedical Applications; Mattiasson, B., Kumar, A., Galaev, I., Eds.; CRC Press: Boca Raton, FL, USA, 2010; pp. 131-154. ISBN 978-1-4200-8461-6.

47. Rodionov, I.A.; Grinberg, N.V.; Burova, T.V.; Grinberg, V.Y.; Lozinsky, V.I. Cryostructuring of polymeric systems. 40. Proteinaceous wide-pore cryogels generated by the action of denaturant/reductant mixtures on bovine serum albumin in moderately-frozen aqueous media. Soft Matter 2015, 11, 4921-4931. [CrossRef] 
48. Van Vlierberghe, S.; Dubruel, P.; Schacht, E. Biopolymer-based hydrogels as scaffolds for tissue engineering applications: A review. Biomacromolecules 2011, 12, 1387-1408. [CrossRef]

49. Zhang, H.; Cooper, A.I. Aligned porous structures by directional freezing. Adv. Mater. 2007, 19, 1529-1533. [CrossRef]

50. Kumar, A.; Mishra, R.; Reinwald, Y.; Bhat, S. Cryogels: Freezing unveiled by thawing. Mater. Today 2010, 13, 42-44. [CrossRef]

51. Okay, O.; Lozinsky, V.I. Synthesis, structure-property relationships of cryogels. Adv. Polym. Sci. 2014, 263, 103-157. [CrossRef]

52. Reichelt, S. Introduction to macroporous cryogels. Methods Mol. Biol. 2015, 1286, 173-181. [CrossRef]

53. Nikonorov, V.V.; Ivanov, R.V.; Kil'deeva, N.R.; Bulatnikova, L.N.; Lozinsky, V.I. Synthesis and characteristics of chitosan cryogels crosslinked by glutaric aldehyde. Polym. Sci. A 2010, 52, 828-834. [CrossRef]

54. Sergeev, G.B.; Batyuk, V.A. Reactions in the multicomponent frozen systems. Russ. Chem. Revs. 1976, 45, 391-408. [CrossRef]

55. Wolfe, J.; Bryant, G.; Koster, K.L. What is unfreezable water, how unfreezable is it and how much is there? CryoLetters 2002, 23, 157-166. [PubMed]

56. Franks, F. (Ed.) Water and Aqueous Solutions at Subzero Temperatures; Plenum Press: New York, NY, USA; London, UK, 1982; p. 484. ISBN 978-1-4757-6954-8.

57. Lozinsky, V.I.; Okay, O. Basic principles of cryotropic gelation. Adv. Polym. Sci. 2014, 263, 49-101. [CrossRef]

58. Wang, C.E.; Jiang, W.; Han, G.T.; Zhang, Y.M. Effect of heat-transfer capability on micropore structure of freeze-drying alginate scaffold. Mater. Sci. Eng. C Mater. Biol. Appl. 2018, 93, 944-949. [CrossRef]

59. Masse, M.A.; Kiran, E.; Fricke, A.L. Freezing and glass-transition phenomena in polymer-diluent mixtures. Polymer 1986, 27, 619-622. [CrossRef]

60. Hallett, J. How snow crystals grow. Am. Sci. 1984, 72, 582-589.

61. Libbrecht, K.G. The physics of snow crystals. Rep. Prog. Phys. 2005, 68, 855-895. [CrossRef]

62. Yakoyama, F.; Achife, E.C.; Momoda, J.; Shimaura, K.; Monobe, K. Morphology of optically anisotropic agarose hydrogel prepared by directional freezing. Coll. Polym. Sci. 1990, 268, 552-558. [CrossRef]

63. Podorozhko, E.A.; Ul’yabaeva, G.P.; Tikhonov, V.E.; Grachev, A.V.; Vladimirov, L.V.; Antonov, Y.A.; Kil'deeva, N.R.; Lozinsky, V.I. A study of cryostructuring of polymer systems. 43. Characteristics of microstructure of chitosan-containing complex and composite poly(vinyl alcohol) cryogels. Colloid J. 2017, 79, 94-105. [CrossRef]

64. Zmora, S.; Glickis, R.; Cohen, S. Tailoring the pore architecture in 3-D alginate scaffolds by controlling the freezing regime during fabrication. Biomaterials 2002, 23, 4087-4094. [CrossRef]

65. Gun'ko, V.M.; Savina, I.N.; Mikhalovsky, S.V. Cryogels: Morphological, structural and adsorption characterization. Adv. Colloid Interface Sci. 2013, 187-188, 1-46. [CrossRef]

66. Cheng, Q.; Huang, C.; Tomsia, A.P. Freeze casting for assembling bioinspired structural materials. Adv. Mater. 2017, 29, 1703155. [CrossRef]

67. Narayan, R. (Ed.) Biomedical Materials; Springer-Verlag US: Boston, MA, USA, 2009; p. 546. ISBN 978-0-378-84872-3.

68. Hamphrey, P.R.; Dale, M.M.; Ritter, J.M.; Flower, R.J.; Henderson, G. Rang E Dale's Pharmacology, 7th ed.; Churchill Livingstone: London, UK, 2011; p. 792, ISBN 978-0702034718.

69. Donati, I.; Paoletti, S. Materials properties of alginates. In Alginates: Biology and Applications; Rehm, B.H.A., Ed.; Microbiology Monographs; Springer: Berlin/Heidelberg, Germany, 2009; pp. 1-53. ISBN 978-3-540-92678-8.

70. Shoichet, M.S. Polymer scaffolds for biomaterials applications. Macromolecules 2010, 43, 581-591. [CrossRef]

71. Caló, E.; Khutoryanskiy, V.V. Biomedical applications of hydrogels: A review of patents and commercial products. Eur. Polym. J. 2015, 65, 252-267. [CrossRef]

(C) 2019 by the authors. Licensee MDPI, Basel, Switzerland. This article is an open access article distributed under the terms and conditions of the Creative Commons Attribution (CC BY) license (http://creativecommons.org/licenses/by/4.0/). 